\title{
Subscapular system free flaps for oromandibular reconstruction
}

\author{
Amy P. Bansal, Marisa R. Buchakjian \\ Department of Otolaryngology - Head \& Neck Surgery, University of lowa Hospitals and Clinics, lowa City, IA 52242, USA. \\ Correspondence to: Dr. Marisa R. Buchakjian, Department of Otolaryngology - Head \& Neck Surgery, University of lowa \\ Hospitals and Clinics, 200 Hawkins Dr, lowa City, IA 52242, USA. E-mail: Marisa-Buchakjian@uiowa.edu
}

How to cite this article: Bansal AP, Buchakjian MR. Subscapular system free flaps for oromandibular reconstruction. Plast Aesthet Res 2021;8:59. https://dx.doi.org/10.20517/2347-9264.2021.45

Received: 10 May 2021 First Decision: 24 Jun 2021 Revised: 13 Jul 2021 Accepted: 29 Sep 2021 Published: 5 Nov 2021

Academic Editors: Matthew Spector, Damien Grinsell Copy Editor: Xi-Jun Chen Production Editor: Xi-Jun Chen

\begin{abstract}
The subscapular system can confer numerous flaps for the reconstruction of composite mandibular defects. This chapter aims to review the indications, advantages, and anatomy of subscapular system flaps in the reconstruction of the mandible. The subscapular system can serve as an alternative to the fibula free flap in the presence of significant atherosclerotic disease or other contraindications. The flexibility and abundance of its soft tissue components make this system particularly advantageous for complex composite defects. Avoiding a fibula free flap for osseous reconstruction of the mandible permits early patient mobilization and may prevent adverse postoperative complications. A long pedicle can be harvested with subscapular flaps, which may prove useful in the face of limited available recipient vessels. Critics of the subscapular system cite longer operative times due to the need for patient repositioning and concerns over the integrity of the bone stock. Positioning modifications may permit a two-team approach to subscapular reconstruction, thus limiting operative times. Subscapular harvest does incur shoulder morbidity; however, this does not appear to affect the quality of life significantly. The flap is reliable and can support endosseous implants if properly planned, though it may be more susceptible to bone resorption when compared to the fibula. Overall, the subscapular system remains a versatile donor that can achieve ideal reconstructive outcomes with minimal morbidity.
\end{abstract}

Keywords: Subscapular free flap, scapular tip, lateral scapular border free flap, segmental mandibulectomy, oromandibular reconstruction 


\section{INTRODUCTION}

Oromandibular defects are among the most complex in head and neck reconstruction. The integrity of the oromandibular complex is essential for optimal function of swallow, speech, and breathing. Restoration of mandibular continuity, articulation, and mastication are critical considerations in choosing the donor site tissue and reconstructive plan ${ }^{[1]}$. The need for an osseous reconstructive component able to withstand the forces of mastication limits potential donor site vascularized bone graft options. Additionally, many oral cavity defects have significant soft tissue requirements, which may not be optimally addressed by the frequently thin soft tissue components of common osseous flaps, thus necessitating a second flap.

The primary goals of oromandibular reconstruction are the reestablishment of mandibular continuity and recreation of soft tissue bulk and surface area. Vascularized bone provides the ideal substrate for bony reconstruction due to its ability to withstand biomechanical stresses endured by the mandible and resistance to infection compared to nonvascularized reconstructive options ${ }^{[2]}$. The iliac crest, fibula free flap, osteocutaneous radial forearm flap (OCRFF), and scapular free flaps have all emerged as potential donor sites for mandibular reconstruction ${ }^{[3]}$. Appreciation of the benefits and drawbacks of each is essential in the selection of donor sites and optimization of reconstructive outcomes. Historically, the osteocutaneous iliac crest flap had been favored for its hearty bone stock and ease of dissection. However, its usage in oromandibular reconstruction has been limited by a bulky skin paddle, resultant gait disturbance, potential for incisional hernia, inability to perform shaping osteotomies, injury to the lateral femoral cutaneous nerve, and susceptibility toward wound complications ${ }^{[4]}$. OCRFF is advantageous because it readily permits a twoteam approach; however, the limited length of bone graft available, donor site morbidity, and inability to place dental implants due to thin bone stock has diminished its widespread adoption ${ }^{[4]}$. The fibula free flap is characterized by its sufficient cortical bone stock, ample bone and pedicle length, thin pliable skin paddle, and ease of two-team harvest. It has emerged as the predominant workhorse flap in mandibular reconstruction. Despite this, the presence of significant peripheral vascular disease, aberrant vascular anatomy, or previous extremity trauma may preclude the use of the fibula in some patients. Donor site morbidity related to gait disturbances and the need for prolonged immobilization may make the fibula a less favorable option in vulnerable populations, especially the elderly and those with occupational dependence on ambulation. In addition, the limited soft tissue bulk available with the fibula flap may prove insufficient to restore function in complex oral cavity defects requiring substantial soft tissue and mucosal reconstruction ${ }^{[1]}$.

The subscapular system offers a versatile selection of flaps that have been well-described and lauded for its ability to reconstruct complex three-dimensional defects. This system offers three potential skin paddles, two muscle flaps, and three sources of bone, with the potential for conjoined or chimeric variations allowing for significant reconstructive flexibility ${ }^{[5,6]}$. Reliable transfer of lateral scapular border osteocutaneous flaps in the head and neck was popularized by Swartz et al. ${ }^{[7]}$ over three decades ago. The lateral scapular border latissimus dorsi osteomyocutaneous chimeric free flap remains the gold standard for oral cavity reconstruction in the subscapular system to this day. Further iterations of flaps based on the angular artery extending to the more caudal scapular tip and latissimus dorsi chimeric flap were later described by Coleman and Sultan ${ }^{[8]}$. Recent literature has reflected a trend toward the usage of the scapular tip, likely due to the ease of dissection, minimal disruption of rotator cuff muscle attachments, and favorable pedicle length ${ }^{[9-11]}$. In addition, successful use of the latissimus dorsi-serratus-rib complex in mandibular reconstruction has also been described as a salvage osseous option ${ }^{[4]}$. 


\section{DISCUSSION}

\section{Indications and contraindications for subscapular free flaps in oromandibular reconstruction}

Primary indications for subscapular flaps include the need for a complex or substantial soft tissue component and the inability to use a fibula free flap on a given patient. The flexibility to independently orient the soft tissue and osseous components of subscapular flaps make them ideal candidates for fullthickness defects of the cheek, lip, and tongue ${ }^{[12]}$. For many groups, the fibula free flap remains the workhorse of vascularized bone grafting in mandibular reconstruction. However, its skin paddle is thin, and the range of motion is limited by the course of its perforator. The fibula offers limited bone height, which may be inadequate in achieving the desired functional outcomes ${ }^{[13]}$. Subscapular system flaps provide ample and diverse soft tissue components and, in some situations, can be contoured to match the bone height of the native mandible. It is ideal for mandibular defects with concomitant large-bulk soft tissue reconstruction such as near-total or total glossectomy, oropharyngectomy, or in the face of dual surface reconstruction. Furthermore, usage of the fibula may be precluded by the presence of significant peripheral atherosclerotic or thrombotic disease. When donor site function and mobility are crucial for occupational or daily activities, it may be important for the surgeon to opt for the subscapular flap ${ }^{[0,13,14]}$. Use of the subscapular system instead of the fibula allows for early mobilization and relatively quick donor site wound healing and minimizes the risks associated with prolonged immobility ${ }^{[5]}$. This may be particularly important in high-risk patient populations such as the elderly or those with significant cardiopulmonary comorbidities.

Few contraindications exist for subscapular flaps. Prior axillary dissection or ipsilateral radiation may deter the use of a shoulder in favor of the contralateral shoulder or other donor sites ${ }^{[15]}$. Longer osseous defects (> $14 \mathrm{~cm}$ ) with anterior mandibular defects requiring multiple osteotomies may be better served with a fibular free flap ${ }^{[10,16,17]}$. Harvest of the subscapular flap in the lateral decubitus position requires turning the patient and multiple preparations which may increase the operative time. Surgeon preference and experience harvesting the subscapular system may also determine the choice of the donor site.

\section{Subscapular anatomy}

The subscapular system provides a diverse array of available flaps based on the combination of its components [Figure 1]. Osseous donors include the lateral scapular border (supplied by the circumflex scapular artery, CSA), scapular tip (angular artery), and rib (branch to serratus anterior). Bone harvest can extend from approximately $1 \mathrm{~cm}$ below the glenohumeral joint and may include the lateral scapular border to the scapular tip ${ }^{[10,14]}$. Scapular fasciocutaneous and parascapular fasciocutaneous flaps are supplied by the CSA. Fasciocutaneous perforators from the thoracodorsal artery (TDA) can be dissected through the latissimus dorsi muscle to a fasciocutaneous paddle without the need to harvest muscle (thoracodorsal artery perforator flap, TDAP). The latissimus dorsi, serratus anterior, and teres major may provide sources of muscle for subscapular flaps.

The subscapular artery originates from the axillary artery then divides into the CSA and TDA. In some cases, the CSA and TDA may arise independently from the axillary artery ${ }^{[18]}$. The CSA travels through the triangular space created by the boundary of the teres major, teres minor and long head of the triceps to divide into transverse and cutaneous branches. Two vena comitantes accompany the CSA. Along this course, it supplies muscular, periosteal, and cutaneous branches ${ }^{[14]}$. Periosteal branches supply the lateral scapular border with a pedicle length estimated at $6 \mathrm{~cm}^{[19]}$. The teres major muscle may also serve as a less bulky alternative to the latissimus dorsi flap or adjunct to the lateral scapular border flap ${ }^{[20]}$. The transverse branch supplies the scapular fasciocutaneous flap, which overlies the latissimus dorsi muscle. The descending branch supplies the parascapular fasciocutaneous flap ${ }^{[16]}$. Approximately 7-10 $\mathrm{cm}$ of pedicle can be obtained from CSA to the fasciocutaneous components ${ }^{[16]}$. 

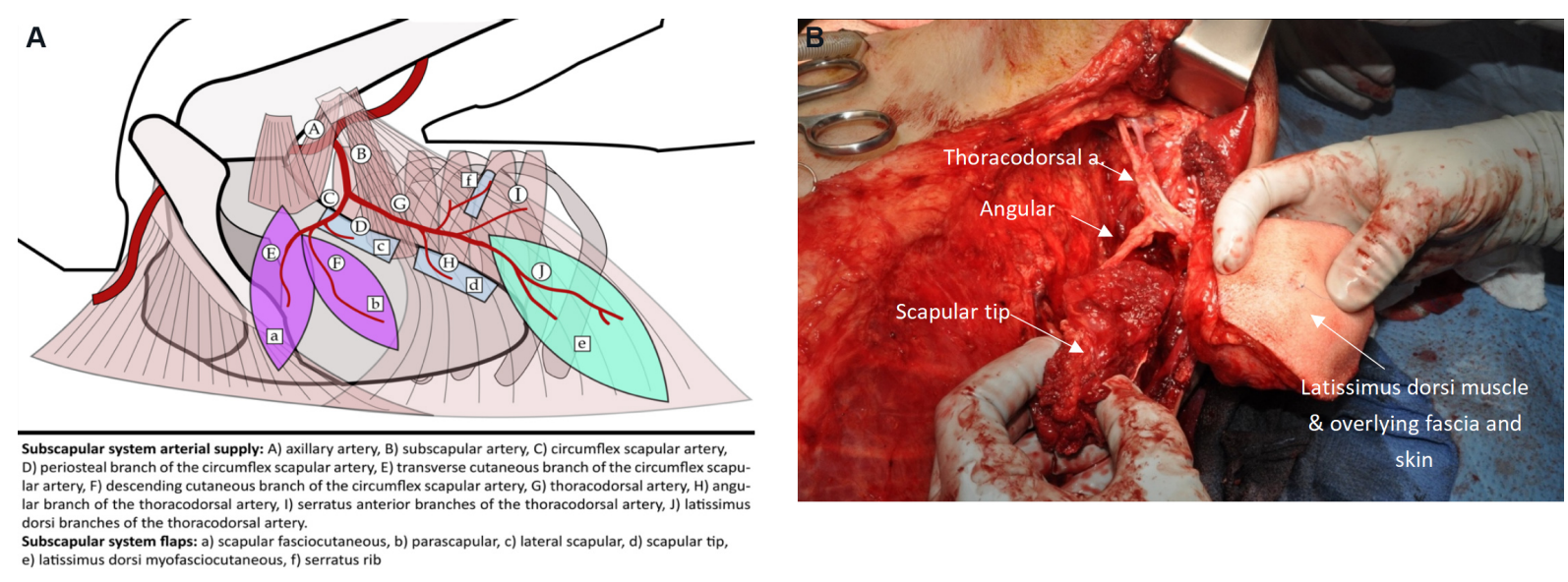

Figure 1. (A) Subscapular system anatomy showing blood supply to fasciocutaneous (purple), myofasciocutaneous (green), and osseous (blue) components. (B) Intraoperative photograph of left latissimus dorsi - scapular tip chimeric free flap harvest.

The TDA travels parallel to the lateral border of the scapula before entering the hilum of the latissimus dorsi muscle. It serves as the primary blood supply to the muscle superolaterally ${ }^{[21]}$. The more inferior and medial portions of this muscle are supplied by intercostal and lumbar arteries ${ }^{[16]}$. Along its course, it most commonly provides branches to the scapula tip, serratus anterior, as well as muscular branches to the subscapularis and teres major ${ }^{[14]}$. TDA pedicle length has been estimated between 15 to $20 \mathrm{~cm}$. Longer pedicles $(\sim 27 \mathrm{~cm})$ can be obtained by dissection of thoracodorsal artery perforators ${ }^{[21]}$. The angular artery typically arises from the TDA but may arise from the branch to the serratus anterior; thus, it is important to completely define the subscapular vascular anatomy prior to dividing any vascular branches. The angular artery travels along the lateral border of the scapula and provides periosteal feeders to the scapular tip along the deep surface of the bone. The angular artery can be between 2.5 and $8 \mathrm{~cm}$, and together with the TDA, the mean pedicle length is approximately 14 to $17 \mathrm{~cm}^{[21-24]}$. Ultimately, the available pedicle length to reach recipient vessels is also influenced by the orientation of the pedicle to the defect. The TDA can be inset either medial or lateral to the scapula bone, with medial orientation resulting in less compression of the TDA but an overall shorter pedicle length.

\section{Advantages of subscapular free flaps}

The principal advantage of subscapular system flaps is the versatility of soft tissue reconstruction. Cutaneous or myofascial flap components may be oriented with a considerable range of motion from the bone, making it well adapted for complex multi-surface reconstruction ${ }^{[1,25]}$. Chimeric selections of the subscapular system can be oriented independently of one another to achieve superior spatial reconstruction. Functional restoration of deglutition and speech relies primarily on the reconstitution of volume and articulatory surface in the oral cavity ${ }^{[26]}$. The quantity of soft tissue offered by this system is unmatched by other donor $\operatorname{sites}^{[27]}$. Chimeric options, as well as the potential incorporation of local perforators with myofascial insertions into the scapular tip, latissimus dorsi muscle and serratus provide an ample offering of muscle and overlying fasciocutaneous options $s^{[10,11,27]}$. A case series published by Ferrari et al.$^{[28]}$ described a technique involving the thoracodorsal artery perforator flap - scapular tip to reconstruct near-total and total glossectomy defects. In this series, all patients were able to achieve intelligible speech, demonstrating the capacity for functional restoration of oral function in the setting of optimal soft tissue reconstruction.

Composite defects of the mandible and oral cavity require multiple anatomic components that previously were frequently treated with dual free flaps [Figure 2]. The application of osteomyocutaneous subscapular flaps can reduce the need for multiple free flaps, thus avoiding longer operative times, increased 

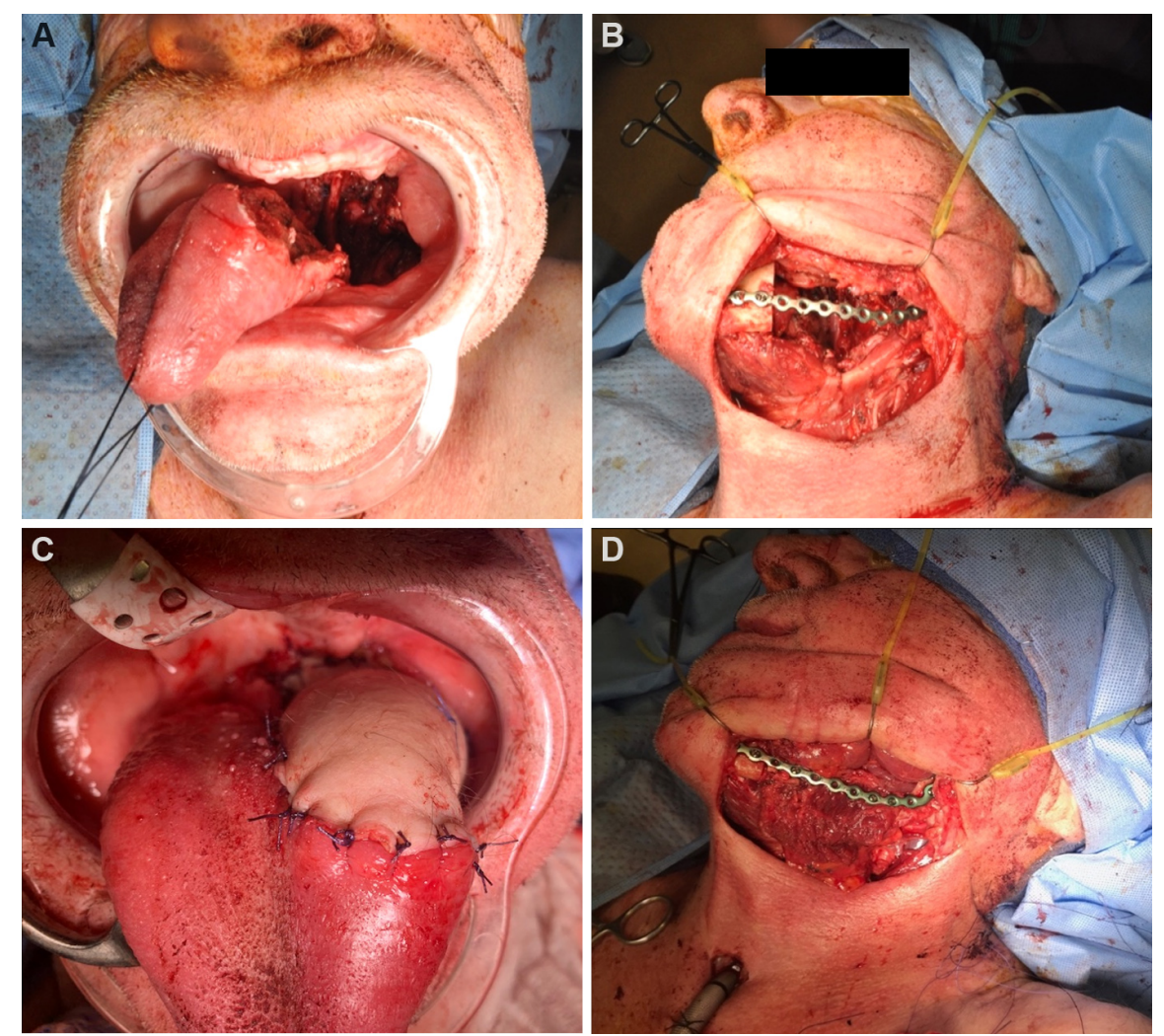

Figure 2. (A) Composite mandibulectomy defect involving oral tongue and oropharynx. (B) Intraoperative lateral view of mandibulectomy defect with the custom mandibular plate in place. (C) Inset of latissimus dorsi fasciomyocutaneous flap into soft tissue defect. (D) Scapular tip inset for the reconstruction of neomandible.

perioperative complications, and the morbidity of multiple donor sites. A systematic review of outcomes of chimeric flaps found that dual independent flaps were associated with a higher rate of flap loss when compared to chimeric flaps ${ }^{[6]}$. Reports in the literature have demonstrated its utility in the reconstruction of near-total lip and through and through defects of the lower face, suggesting that in the appropriate situation, a second free flap would be unnecessary ${ }^{[12,29]}$. Additionally, a single composite free flap avoids the need for multiple anastomoses, which may be advantageous in the vessel-depleted or previously treated neck ${ }^{[1,19,21]}$. Flaps derived from the subscapular system may also be readily combined with locoregional head and neck flaps to allow for superior cosmetic and functional outcomes. A case series describing the use of osteocutaneous subscapular flaps in conjunction with an Estlander flap showed preservation of oral sphincter control, which was a notable improvement over static reconstructive options offered by a second free flap ${ }^{[30]}$.

The fascia and skin overlying the latissimus dorsi muscle provide a largely available skin paddle for free tissue transfer, with a superior color match for the head and neck compared to leg and arm tissue and a more acceptable donor site $\operatorname{scar}^{[10,19,22,31]}$. The superior mobility of the latissimus muscle and skin paddle along the thoracodorsal pedicle can permit a tension-free inset nearly anywhere in the oral cavity and the bulk of the muscle and adiposity of the skin paddle may prevent significant contraction related to healing and radiation ${ }^{[13]}$. In addition, the relatively large soft tissue components may offer improved coverage of hardware and obliterate dead space to provide an adequate seal of the oral mucosa and help prevent fistula during the healing process ${ }^{[32,33]}$. 
Subscapular flaps offer distinct advantages over other osteomyocutaneous donors. Perhaps the most important is the relative lack of intimal disease found in the vasculature ${ }^{[1,1,1,21,34,35]}$. In contrast, fibula flaps may be contraindicated due to the burden of atherosclerosis in the lower extremities. Moreover, the presence of peripheral vascular disease may affect the microcirculation and overall viability of these flaps, which is difficult to predict upfront and may result in partial or complete flap loss. In addition, risks associated with prolonged immobility in the postoperative period, such as deep vein thrombosis, atelectasis, and pneumonia, are minimized when the lower extremities are spared ${ }^{[10,33,34]}$. A retrospective review of perioperative morbidity following scapular tip flaps found that the return to ambulation was 2.7 days, compared with the average of 4 to 6 days with fibula flaps ${ }^{[36]}$. The shoulder does not require post-operative immobilization, but early physical therapy is recommended to prevent adhesive capsulitis and decreased range of motion. Patients most susceptible to perioperative complications, such as the elderly or patients with poor functional status, may be better served by subscapular flaps to increase mobilization and functional status postoperatively.

The relatively low morbidity and complication rate of subscapular flaps make this system a favorable choice for free tissue transfer. Fujiki et al. ${ }^{[33]}$ reviewed their experience with scapular vs. fibula flaps and found that though the overall complication rate was similar, fibula donor sites incurred more donor site morbidity. Shoulder morbidity is of particular concern with scapular flaps; however, studies have suggested that despite a deficit in the range of motion, activities of daily living are not significantly affected for patients ${ }^{[10,11,34]}$. Kearns et al. ${ }^{[37]}$ reviewed complications and morbidity following osteocutaneous free flaps in the head and neck and reported the lowest morbidity among scapular flaps, with the fibula and radial forearm flaps demonstrating higher rates of delayed wound healing. Avoidance of skin grafting makes the subscapular system relatively free of the risk of delayed donor site healing and avoids the need for an additional surgical site for a split-thickness skin graft. Tsang et al. ${ }^{[32]}$ related their experience among scapular and fibula flaps in oromandibular reconstruction and found that fibula flaps sustained a significantly higher rate of postoperative hardware exposure. Tsang et al. ${ }^{[32]}$ submit that this may be due to the chimeric nature of most scapular flaps and the abundance of soft tissue available for reconstruction ${ }^{[32]}$. Scapular flaps provide the added benefit of potentially adjustable morbidity. The proportion of bone harvested is commensurate to the defect, whereas a fibula or iliac crest harvest would incur the same morbidity regardless of the defect size, requiring resection of a large segment of donor bone to allow for sufficient pedicle length ${ }^{[38]}$.

The osseous portion of the scapula has notable advantages over the fibula bone and other osteocutaneous flaps. The bone height available with scapular flaps is potentially greater than the fibula bone, depending on the planned orientation of the scapula inset. This has important functional considerations. Sufficient bone height of the mandible can act as a strut for the lower lip and prevent retrodisplacement of the lip at baseline $^{[12,13]}$. The vertical height of the neomandible may also affect oral competence by mimicking the gingivobuccal sulci. Jacobson et al. ${ }^{[12]}$ presented a case report using a technique to extend the osteotomy along the scapula medially to improve bone height equity further, with adequate oral competence and intelligible speech achieved postoperatively. The native contour of the scapula may also mimic the mandibular angle, thus eliminating the need for osteotomies and potential graft compromise. Additionally, the horizontal orientation of the scapula bone permits reconstruction of symphyseal defects with similar projection and contour to the native mandible without the need for closing osteotomies ${ }^{[39]}$.

Less popular options for osseous reconstruction include the latissimus-serratus anterior rib free flap. Up to five slips of serratus muscle can be harvested on a single vascular pedicle, each with the ability to be oriented independently from one another. However, bone resorption and inability to place implants have restricted the utility of the serratus-rib flap in mandibular reconstruction, though this may be an option for salvage 
reconstruction when other osseous donors are unavailable. Additionally, it may be preferred for the reconstruction of the temporomandibular joint complex ${ }^{[4]}$.

Early reports on scapular flaps described the use of the lateral scapular border based on the circumflex scapular artery. However, the scapular tip has become increasingly recognized for its distinct advantages over the lateral scapular border in recent years. Isolation of the angular artery along the thoracodorsal or serratus branches provides a long pedicle length of up to $17 \mathrm{~cm}^{[2,38]}$. This attribute is particularly useful in previously treated or vessel-depleted necks and might avoid the need for a vein graft to reach more inferior vessels such as the transverse cervical artery and vein ${ }^{[2,40,4]}$. Utilization of a chimeric or conjoined subscapular flap over dual free flaps avoids the need for two separate anastomoses in patients with limited recipient vessel options. Though initially reported to be ideal in the reconstruction of linear mandibular defects with complex soft tissue requirements, the collective experience reported in the literature highlights the versatility of the scapular tip in the reconstruction of any portion of the mandible. The contour of the distal scapular border and the scapular tip are readily suitable for the reconstruction of the mandibular angle and mandibular body when oriented vertically and the mandibular symphysis when oriented horizontally ${ }^{[2,25]}$. Reports have demonstrated the viability of contouring osteotomies in scapular tip flaps despite its periosteal blood supply, allowing even more flexibility in reconstructive approaches ${ }^{[17,25,29]}$. Successful reconstruction of the condyle-ramus unit and short segmental vertical ramus defects have been published ${ }^{[1,38]}$. The horizontal orientation of the scapular tip can be used to reconstruct anterior mandibular defects without the need for osteotomy, with comparable projection and width to native mandibular measurements ${ }^{[39]}$.

The use of preoperative computer-based surgical planning (Individual Patient Solutions, KLS Martin) can be a valuable adjunct in planning flap harvest and achieving the desired reconstructive outcome. Preoperative computed tomography (CT) imaging with thin slices $(1.25 \mathrm{~mm})$ is obtained of the mandible and the shoulder. Virtual three-dimensional renderings of the defect and scapular bone can then be oriented and simulated to reconstruct the desired outcome. The flap can be planned in the horizontal or vertical plane depending on the requirements and location of the defect, with computer modeling ultimately aiding in this decision-making. A scapular bone reconstructive segment model may be provided to act as a guide for planning the harvest, facilitating the two-team surgical approach, decreasing operative time, and increasing accuracy [Figure 3]. In the case where osteotomies are planned for the scapula bone, custom cutting guides may be fabricated to allow optimal alignment, decreasing the operative time needed for manual contouring.

\section{Disadvantages of subscapular system flaps in oromandibular reconstruction}

Perhaps the most widely cited drawback to the use of subscapular flaps is the concern for increased operative time $\mathrm{e}^{[33]}$. Previous descriptions of subscapular harvest described a lateral decubitus position, which necessitated intraoperative repositioning and prepping of the patient. With this positioning, an assistant was required to retract the arm to aid in abduction and rotation during harvest and closure. In addition, donor site closure was performed prior to repositioning the patient for inset and microvascular anastomosis, prolonging ischemia time and total operative time. Recent reports of positioning modifications in the semilateral decubitus position and supine positioning with limb suspension have made significant advances in improving operational efficiency and enabled two-team approaches [Figure 4 $]^{[38,42,43]}$. Application of the upper extremity limb positioner (Spider Limb Positioner, Smith \& Nephew), commonly used in orthopedic procedures, has significantly decreased operative times and facilitated flap harvest by reducing the number of assistants required near the operative field ${ }^{[4,45]}$. In addition, the positioner can be adjusted intraoperatively by the surgeon to permit access to the ipsilateral head and neck when necessary. By utilizing an upper extremity limb positioner, two teams may operate simultaneously, and the subscapular 

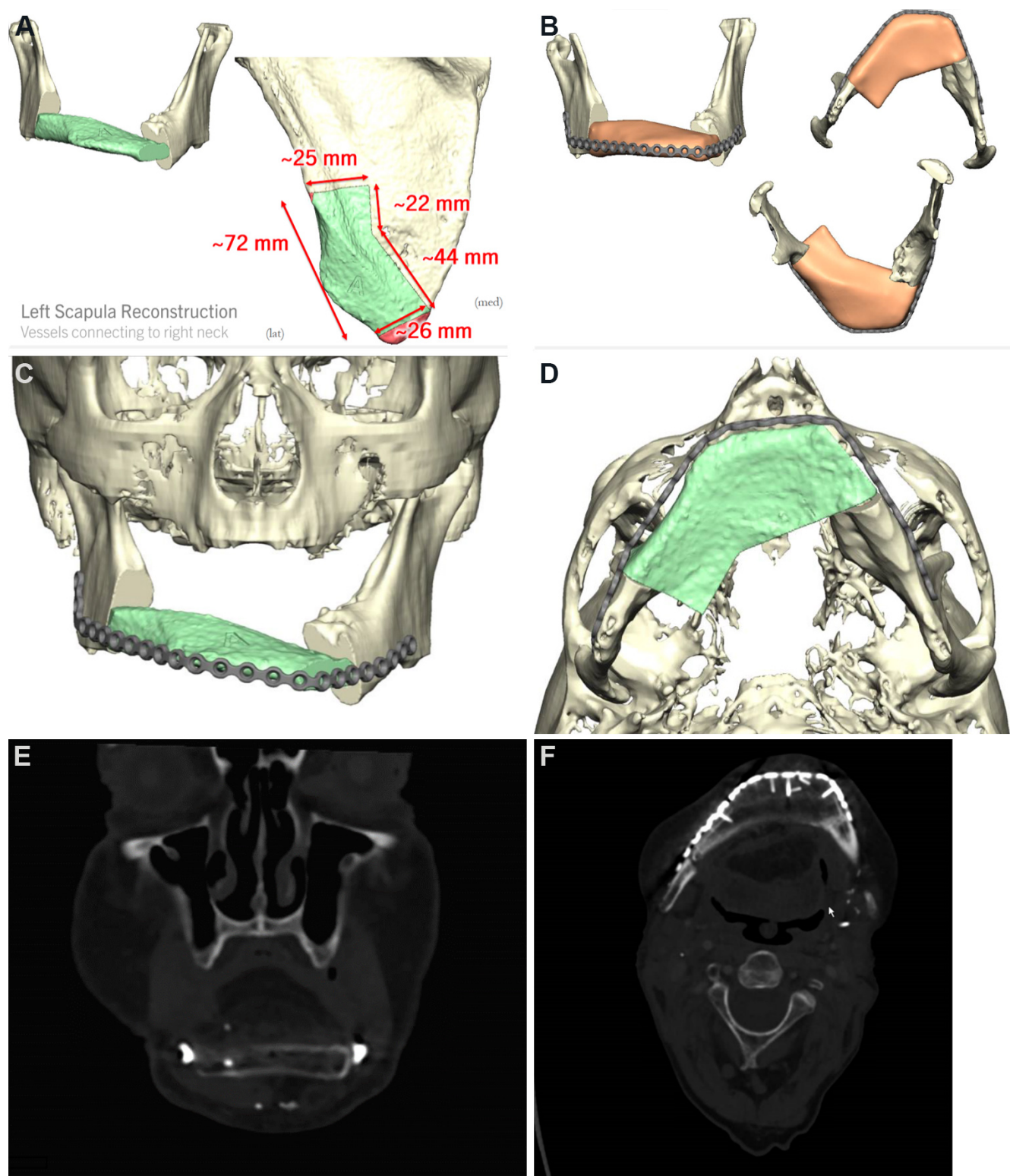

Figure 3. (A) Individual Patient Solutions (IPS, KLS Martin) customized preoperative surgical plan with proposed osteotomy and inset. (B) Computerized three-dimensional rendering of scapular tip model inset into mandibulectomy defect using a customized titanium plate. (C) Coronal computerized rendering of scapular bone inset into mandibulectomy defect. (D) Axial view. (E) Coronal CT performed 8 months postoperatively showing the horizontal projection of scapular bone. (F) Axial view of neomandible.

flap can be readily raised while the ablative surgeons complete their portion of the procedure.

Concerns over available bone stock and length have also impaired acceptance of the subscapular flap, particularly in the reconstruction of mandibular defects. Scapular bone lacks the bone stock afforded by the iliac crest and thick cortical bone of the fibula ${ }^{[1]}$. The scapular tip can reliably provide up to $9 \mathrm{~cm}$ of bone length based on the periosteal supply ${ }^{[2,25]}$. Segments 10 to $14 \mathrm{~cm}$ have been harvested from the lateral scapular border ${ }^{[16]}$. The general consensus regarding the need for bone length has reserved reconstruction of longer osseous defects $(>12 \mathrm{~cm})$ to the fibula flap ${ }^{[10,39,41]}$. Despite this, several groups have related their experience successfully reconstructing over $10 \mathrm{~cm}$ of bone from the scapular tip ${ }^{[25]}$. Larger segments of 


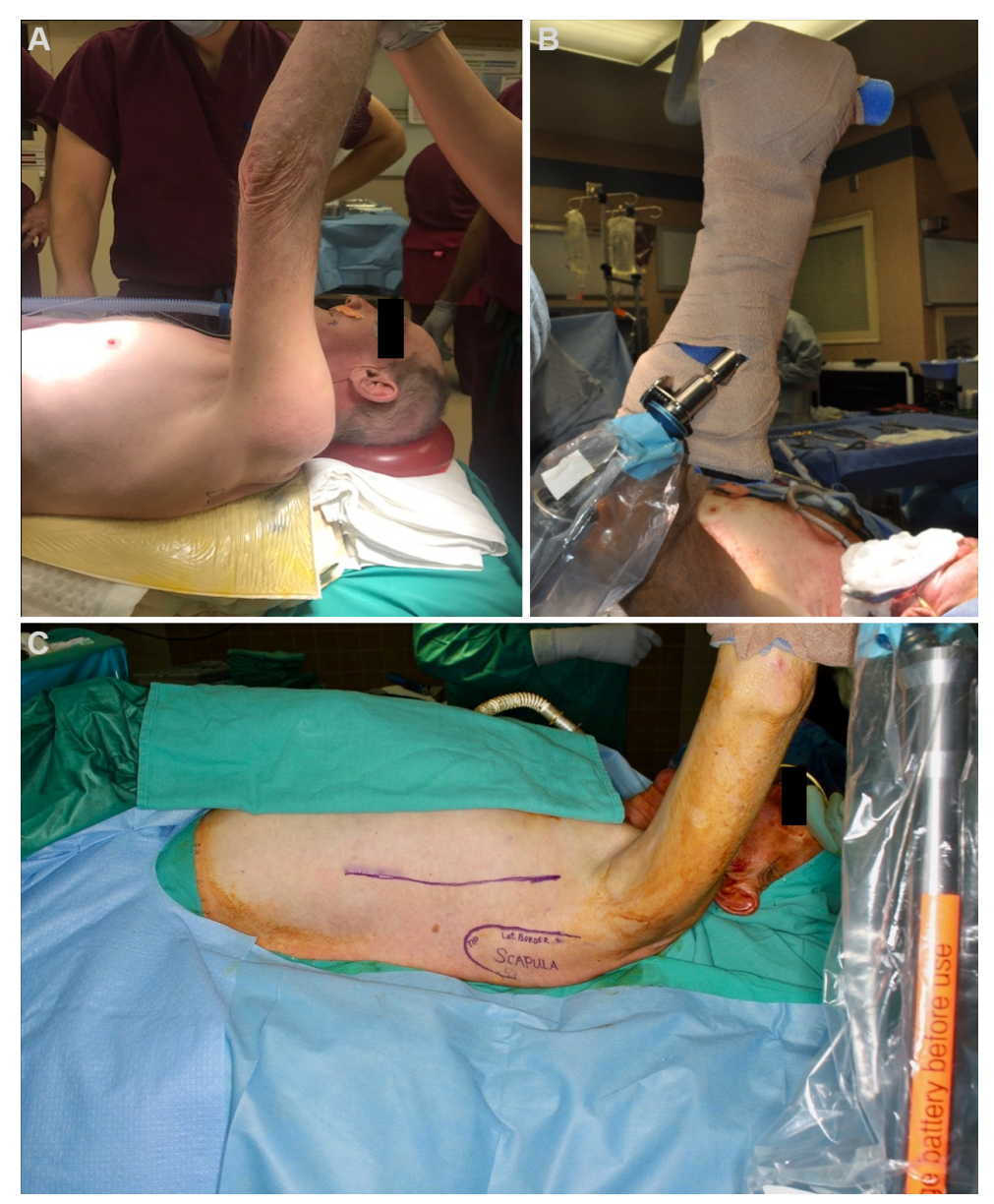

Figure 4. (A) Patient positioning in the semi-lateral decubitus position on a beanbag, showing the exposure of lateral scapular border and tip. (B) Intraoperative forearm positioning using upper extremity limb positioner (Spider Limb Positioner, Smith \& Nephew). (C) Intraoperative view of shoulder positioning and operative field.

scapula bone can be safely obtained by extending osteotomies to include both the lateral scapular border supplied by the circumflex scapular artery and the scapular tip supplied by the angular artery but with a limited pedicle length $(\sim 4 \mathrm{~cm})^{[43,46]}$. Reports of successful hemimandibular reconstruction using scapular bone have expanded the flap's potential indications in the head and neck ${ }^{[44,46]}$. A study of three-dimensional modeling of preoperative CT suggests that the scapular tip may even be suitable for defects extending from the vertical plane of the condyle to beyond the symphysis ${ }^{[44]}$. Despite these reports, many groups remain uncertain about the reliability of scapular bone in large-segment mandibular reconstruction ${ }^{[13]}$.

Initial studies expressed some uncertainty over the long-term complications and limitations of scapular bone. Skepticism remains over the potential for prosthetic rehabilitation with scapular bone ${ }^{[47]}$. The lack of bicortical structure was felt to be unsuitable for osseointegrated implants; however, more recent reports have demonstrated successful dental implants into scapula bone ${ }^{[41,46]}$. Inconsistencies of bone thickness among patients, particularly females, raise uncertainty over the scapula bone's ability to bear dental implants and emphasizes the need for careful preoperative planning ${ }^{[48]}$. Some evidence suggests that the ability of the scapula to heal may be suboptimal compared to other osseous flaps. A meta-analysis comparing perioperative complications of vascularized bone flaps suggested a higher rate of nonunion in scapula flaps than the fibula and iliac crest flaps ${ }^{[3]}$. Volumetric analyses of vascularized mandibular 
reconstructions found the highest rate of bone resorption after two years in scapular bone compared to iliac and fibula bone $e^{[49]}$.

\section{Shoulder morbidity}

The components of the subscapular system exert several important functions on the shoulder. The latissimus dorsi muscle functions to adduct, internally rotate and extend the arm at the shoulder. The teres major muscle adducts and internally rotates the arm. The serratus anterior draws the scapula toward the thorax. Harvest of subscapular flaps has the potential to disrupt multiple functions of the shoulder, though the overall morbidity does not tend to affect the quality of life significantly. Limitation of the horizontal extension of the arm above the head was observed in a series of 10 patients following scapular tip free flap harvest. Reports of objective assessments of a range of motion following scapular free flap show limitations persisting six months following surgery. However, subjective assessment of the validated quality of life scores at six months did not report a major disability, and most patients were able to maintain their preoperative functional status ${ }^{[34,50]}$. Patel et al ${ }^{[34]}$ reviewed subjective and objective measurements of shoulder morbidity following scapular surgery and found no significant difference between the scapular tip and lateral scapular border flaps. Preservation of the motor branch of the latissimus dorsi may also reduce morbidity ${ }^{[2,51,52]}$. A case series of patients who underwent thoracodorsal artery perforator flap - scapular tip osteofasciocutaneous flap, which spares the majority of the latissimus dorsi muscle, reported achievement of a preoperative range of motion 14 weeks following surgery ${ }^{[27]}$.

\section{Osseointegration potential}

Dental rehabilitation is important for optimal mastication, speech, and swallow. Evidence shows that edentulous patients who do not achieve adequate oral rehabilitation sustain significant psychological morbidity ${ }^{[5,54]}$. Tissue-borne dentures put untoward strain on soft tissues and are often poorly retained ${ }^{[5]}$. As such, endosseous implants are the gold standard for dental rehabilitation. Though financial limitations may preclude the procurement of implants, they remain important factors in oromandibular reconstruction and should be taken into consideration when planning an osseous free flap.

Accounts of success rates in endosseous implants in scapula bone are variable $e^{[5,56]}$. Implant viability may be affected by many factors, including successful bony union with the native mandible, radiation status, and the presence of residual dentition. Implant and prosthesis stability relies on sufficient bone stock and structural integrity to endure the biomechanical stresses of mastication ${ }^{[54]}$. Though it was once widely believed that scapular bone stock was insufficient for implantation, numerous reports have established their reliability ${ }^{[1,57-60]}$. Preoperative CT review may aid in identifying areas of adequate bone width and height to assist in planning implantation sites, and further planning may occur during preoperative computer-based surgical planning ${ }^{[47,48]}$.

\section{Complications}

Subscapular flaps achieve similar success rates compared to other free flaps in the head and neck ${ }^{[17,61]}$. A retrospective review of 81 scapular tip free flaps cited a 3.7\% failure rate comparable to published bone flap failure rates ${ }^{[3,17]}$. In a review of hardware complications among fibula and scapular flap recipients, a higher rate of hardware exposure was found in the fibula cohort ${ }^{[32]}$. Hardware extrusion has also been reported in up to $9 \%$ of patients undergoing scapula flaps ${ }^{[17]}$. Nonunion has also been recognized in the postoperative period. In a radiographic review of 53 patients who had scapular tip free flaps, 11/53 (20.7\%) showed evidence of bony nonunion at least three months after surgery. Interestingly, five of these patients were asymptomatic, suggesting that nonunion may be more common than suggested by clinical assessment alone $\mathrm{e}^{[17]}$. 
Published reports of complications from subscapular system-free flaps vary widely. An assessment of donor site complications by Yeh et al. ${ }^{[17]}$ in scapular tip free flaps reveals fairly minimal rates of donor site infection, dehiscence, or seroma. These rates may depend on institutional practices, experience, and extent of harvest. Fujiki et al. ${ }^{[33]}$ reviewed complications of scapula and fibula flaps and found comparable rates of systemic and reconstructive site complications between the two flaps but greater donor morbidity with fibula flaps. Subscapular donor sites may fare better in part because they are exempt from the complications of delayed wound healing from skin grafting ${ }^{[37]}$. Additionally, avoiding prolonged immobilization may help facilitate recovery and decrease other perioperative complications.

\section{CONCLUSIONS}

Subscapular flaps are versatile and well-suited for complex composite mandibular reconstruction. The soft tissue contributions are unparalleled in their bulk and versatility, and the osseous donor options in this system are adaptable and appropriate for mandibular reconstruction. This system provides the added benefits of generous pedicle length and a natural contour that can be oriented and tailored as needed for most mandibular defects. The lack of atherosclerotic disease and avoidance of prolonged bed rest may make the subscapular system the preferred choice over the fibula free flap in the appropriate context. Innovations in patient positioning and computer-based preoperative surgical planning can aid in limiting operative times and allow for a two-team approach. These notable attributes merit strong consideration for the subscapular system in the reconstruction of the oromandibular complex.

\section{DECLARATIONS}

\section{Acknowledgments}

We would like to acknowledge Joseph Peterson, MD for his medical illustration.

\section{Authors' contributions}

Made substantial contributions to conception, literature review, and manuscript preparation, editing, and revisions: Bansal AP, Buchakjian MR

Performed data acquisition, as well as provided administrative, technical, and material support: Bansal AP, Buchakjian MR

\section{Availability of data and materials}

Not applicable.

\section{Financial support and sponsorship}

None.

\section{Conflicts of interest}

Both authors declared that there are no conflicts of interest.

\section{Ethical approval and consent to participate}

Not applicable.

\section{Consent for publication}

The study obtained consent from patients.

\section{Copyright}

(c) The Author(s) 2021. 


\section{REFERENCES}

1. Urken ML, Buchbinder D, Costantino PD, et al. Oromandibular reconstruction using microvascular composite flaps: report of 210 cases. Arch Otolaryngol Head Neck Surg 1998;124:46-55. DOI PubMed

2. Genden EM. Head and neck surgery: reconstructive surgery. Master techniques in otolaryngology. 1st ed. Philadelphia: Lippincott Williams \& Wilkins; 2014.

3. Brown JS, Lowe D, Kanatas A, Schache A. Mandibular reconstruction with vascularised bone flaps: a systematic review over 25 years. Br J Oral Maxillofac Surg 2017;55:113-26. DOI PubMed

4. Kim PD, Blackwell KE. Latissimus-serratus-rib free flap for oromandibular and maxillary reconstruction. Arch Otolaryngol Head Neck Surg 2007;133:791-5. DOI PubMed

5. Gibber MJ, Clain JB, Jacobson AS, et al. Subscapular system of flaps: an 8-year experience with 105 patients. Head Neck 2015;37:1200-6. DOI PubMed

6. Ettyreddy AR, Chen CL, Zenga J, Simon LE, Pipkorn P. Complications and outcomes of chimeric free flaps: a systematic review. Otolaryngol Head Neck Surg 2019;161:568-75. DOI PubMed

7. Swartz WM, Banis JC, Newton ED, Ramasastry SS, Jones NF, Acland R. The osteocutaneous scapular flap for mandibular and maxillary reconstruction. Plast Reconstr Surg 1986;77:530-45. DOI PubMed

8. Coleman JJ 3rd, Sultan MR. The bipedicled osteocutaneous scapula flap: a new subscapular system free flap. Plast Reconstr Surg 1991;87:682-92. DOI PubMed

9. Aviv JE, Urken ML, Vickery C, Weinberg H, Buchbinder D, Biller HF. The combined latissimus dorsi-scapular free flap in head and neck reconstruction. Arch Otolaryngol Head Neck Surg 1991;117:1242-50. DOI PubMed

10. Dowthwaite SA, Theurer J, Belzile M, et al. Comparison of fibular and scapular osseous free flaps for oromandibular reconstruction: a patient-centered approach to flap selection. JAMA Otolaryngol Head Neck Surg 2013;139:285-92. DOI PubMed

11. Bianchi B, Ferri A, Ferrari S, et al. Reconstruction of mandibular defects using the scapular tip free flap. Microsurgery 2015;35:101-6. DOI PubMed

12. Jacobson L, Dedhia R, Kokot N, Chalian A. Scapular osteocutaneous free flap for total lower lip and mandible reconstruction. Microsurgery 2016;36:480-4. DOI PubMed

13. Brown J, Bekiroglu F, Shaw R. Indications for the scapular flap in reconstructions of the head and neck. Br J Oral Maxillofac Surg 2010;48:331-7. DOI PubMed

14. Janus JR, Carlson ML, Moore EJ. The scapular, parascapular, and latissimus dorsi flap as a single osteomyocutaneous flap for repair of complex oral defects. Clin Anat 2012;25:120-8. DOI PubMed

15. Robb GL. Free scapular flap reconstruction of the head and neck. Clin Plast Surg 1994;21:45-58. PubMed

16. Urken ML, Cheney ML, Blackwell KE, Harris JR, Hadlock TA, Futran N. Atlas of regional and free flaps for head and neck reconstruction. Wolters Kluwer; 2011. DOI

17. Yeh DH, Lee DJ, Sahovaler A, et al. Shouldering the load of mandible reconstruction: 81 cases of oromandibular reconstruction with the scapular tip free flap. Head Neck 2019;41:30-6. DOI PubMed

18. Kawamura K, Yajima H, Kobata Y, Shigematsu K, Takakura Y. Anatomy of Y-shaped configurations in the subscapular arterial system and clinical application to harvesting flow-through flaps. Plast Reconstr Surg 2005;116:1082-9. DOI PubMed

19. Blumberg JM, Walker P, Johnson S, et al. Mandibular reconstruction with the scapula tip free flap. Head Neck 2019;41:2353-8. DOI PubMed

20. Tomlinson AR, Jameson MJ, Pagedar NA, Schoeff SS, Shearer AE, Boyd NH. Use of the teres major muscle in chimeric subscapular system free flaps for head and neck reconstruction. JAMA Otolaryngol Head Neck Surg 2015;141:816-21. DOI PubMed

21. Chepeha DB, Khariwala SS, Chanowski EJ, et al. Thoracodorsal artery scapular tip autogenous transplant: vascularized bone with a long pedicle and flexible soft tissue. Arch Otolaryngol Head Neck Surg 2010;136:958-64. DOI PubMed

22. O'Connell JE, Bajwa MS, Schache AG, Shaw RJ. Head and neck reconstruction with free flaps based on the thoracodorsal system. Oral Oncol 2017;75:46-53. DOI PubMed

23. Coeugniet E, Harchaoui A, Malka G, Pellerin P, Danino A. [The osteomuscular latissimus dorsi scapula flap: anatomical study and 3 cases]. Ann Chir Plast Esthet 2007;52:108-13. DOI PubMed

24. Seneviratne S, Duong C, Taylor GI. The angular branch of the thoracodorsal artery and its blood supply to the inferior angle of the scapula: an anatomical study. Plast Reconstr Surg 1999;104:85-8. PubMed

25. Tracy JC, Brandon B, Patel SN. Scapular tip free flap in composite head and neck reconstruction. Otolaryngol Head Neck Surg 2019;160:57-62. DOI PubMed

26. Yun IS, Lee DW, Lee WJ, Lew DH, Choi EC, Rah DK. Correlation of neotongue volume changes with functional outcomes after long-term follow-up of total glossectomy. J Craniofac Surg 2010;21:111-6. DOI PubMed

27. Pau M, Wallner J, Feichtinger M, et al. Free thoracodorsal, perforator-scapular flap based on the angular artery (TDAP-Scap-aa): clinical experiences and description of a novel technique for single flap reconstruction of extensive oromandibular defects. $J$ Craniomaxillofac Surg 2019;47:1617-25. DOI PubMed

28. Ferrari M, Sahovaler A, Chan HHL, Nicolai P, Irish JC, Gilbert RW. Scapular tip-thoracodorsal artery perforator free flap for total/subtotal glossectomy defects: case series and conformance study. Oral Oncol 2020;105:104660. DOI PubMed

29. Granick MS, Newton ED, Hanna DC. Scapular free flap for repair of massive lower facial composite defects. Head Neck Surg 1986;8:436-41. DOI PubMed

30. Hamahata A, Saitou T, Beppu T, et al. Complex lower face reconstruction using a combined technique of Estlander flap and 
subscapular artery system free flaps. J Plast Reconstr Aesthet Surg 2013;66:e366-9. DOI PubMed

31. Bach CA, Dreyfus JF, Wagner I, Lachiver X, Guth A, Chabolle F. Comparison of radial forearm flap and thoracodorsal artery perforator flap donor site morbidity for reconstruction of oral and oropharyngeal defects in head and neck cancer. Eur Ann Otorhinolaryngol Head Neck Dis 2015;132:185-9. DOI PubMed

32. Tsang GFZ, Zhang H, Yao C, et al. Hardware complications in oromandibular defects: comparing scapular and fibular based free flap reconstructions. Oral Oncol 2017;71:163-8. DOI PubMed

33. Fujiki M, Miyamoto S, Sakuraba M, Nagamatsu S, Hayashi R. A comparison of perioperative complications following transfer of fibular and scapular flaps for immediate mandibular reconstruction. J Plast Reconstr Aesthet Surg 2013;66:372-5. DOI PubMed

34. Patel KB, Low TH, Partridge A, et al. Assessment of shoulder function following scapular free flap. Head Neck 2020;42:224-9. DOI PubMed

35. Ghassemi A, Köhlen D, Braunschweig T, Modabber A, Prescher A, Nanhekhan L. Histopathological differences of the pedicle artery in commonly used free flaps: the influence of age, gender, and side. J Oral Maxillofac Surg 2016;74:836-43. DOI PubMed

36. Ferrari S, Ferri A, Bianchi B, Varazzani A, Perlangeli G, Sesenna E. Donor site morbidity after scapular tip free flaps in head-and-neck reconstruction. Microsurgery 2015;35:447-50. DOI PubMed

37. Kearns M, Ermogenous P, Myers S, Ghanem AM. Osteocutaneous flaps for head and neck reconstruction: a focused evaluation of donor site morbidity and patient reported outcome measures in different reconstruction options. Arch Plast Surg 2018;45:495-503. DOI PubMed PMC

38. Yoo J, Dowthwaite SA, Fung K, Franklin J, Nichols A. A new angle to mandibular reconstruction: the scapular tip free flap. Head Neck 2013;35:980-6. DOI PubMed

39. Sheehan CC, Haskins AD, Huang AT, Hernandez DJ. Cephalometric and functional mandibular reconstructive outcomes using a horizontal scapular tip free flap. Otolaryngol Head Neck Surg 2021;165:414-8. DOI PubMed

40. Karle WE, Anand SM, Clain JB, et al. Use of a combined latissimus dorsi scapular free flap revascularized with vein grafting to the internal mammary artery in a vessel-depleted and previously irradiated neck. Head Neck 2013;35:E328-32. DOI PubMed

41. Ho MW, Brown JS, Shaw RJ. Refining the indications for scapula tip in mandibular reconstruction. Int J Oral Maxillofac Surg 2017;46:712-5. DOI PubMed

42. Eskander A, Kang SY, Ozer E, et al. Supine positioning for the subscapular system of flaps: a pictorial essay. Head Neck 2018;40:1068-72. DOI PubMed

43. Clark JR, Vesely M, Gilbert R. Scapular angle osteomyogenous flap in postmaxillectomy reconstruction: defect, reconstruction, shoulder function, and harvest technique. Head Neck 2008;30:10-20. DOI PubMed

44. Marchiano E, Stevens JR, Liao E, et al. Three-dimensional modeling of the scapular tip for anterolateral and lateral mandibular defects. Oral Oncol 2020;107:104718. DOI PubMed

45. Bender-Heine A, Young G, Moy J, Weedman S, Wax MK. Application of the spider limb positioner to subscapular system free flaps. Laryngoscope 2021;131:525-8. DOI PubMed

46. Ettinger KS, Alexander AE, Morris JM, Arce K. Novel geometry of an extended length chimeric scapular free flap for hemimandibular reconstruction: nuances of the technique streamlined by in-house virtual surgical planning and 3D printing for a severely vesseldepleted neck. J Oral Maxillofac Surg 2020;78:823-34. DOI PubMed

47. Lanzer M, Gander T, Grätz K, Rostetter C, Zweifel D, Bredell M. Scapular free vascularised bone flaps for mandibular reconstruction: are dental implants possible? J Oral Maxillofac Res 2015;6:e4. DOI PubMed PMC

48. Solis RN, Mahaney J, Mohhebali R, et al. Digital imaging evaluation of the scapula for prediction of endosteal implant placement in reconstruction of oromandibular defects with scapular free flaps. Microsurgery 2019;39:730-6. DOI PubMed

49. Wilkman T, Apajalahti S, Wilkman E, Törnwall J, Lassus P. A comparison of bone resorption over time: an analysis of the free scapular, iliac crest, and fibular microvascular flaps in mandibular reconstruction. J Oral Maxillofac Surg 2017;75:616-21. DOI PubMed

50. Nkenke E, Vairaktaris E, Stelzle F, Neukam FW, Stockmann P, Linke R. Osteocutaneous free flap including medial and lateral scapular crests: technical aspects, viability, and donor site morbidity. J Reconstr Microsurg 2009;25:545-53. DOI PubMed

51. Shaw RJ, Ho MW, Brown JS. Thoracodorsal artery perforator - scapular flap in oromandibular reconstruction with associated large facial skin defects. Br J Oral Maxillofac Surg 2015;53:569-71. DOI PubMed

52. Hamdi M, Decorte T, Demuynck M, et al. Shoulder function after harvesting a thoracodorsal artery perforator flap. Plast Reconstr Surg 2008;122:1111-7. DOI PubMed

53. Rogers SN, Mcnally D, Mahmoud M, Chan MF, Psychol M, Humphris GM. Psychologic response of the edentulous patient after primary surgery for oral cancer: a cross-sectional study. J Prosthet Dent 1999;82:317-21. DOI PubMed

54. Moscoso JF, Keller J, Genden E, et al. Vascularized bone flaps in oromandibular reconstruction. A comparative anatomic study of bone stock from various donor sites to assess suitability for enosseous dental implants. Arch Otolaryngol Head Neck Surg 1994;120:36-43. DOI PubMed

55. Urken ML, Buchbinder D, Weinberg H, Vickery C, Sheiner A, Biller HF. Primary placement of osseointegrated implants in microvascular mandibular reconstruction. Otolaryngol Head Neck Surg 1989;101:56-73. DOI PubMed

56. Laverty DP, Kelly R, Addison O. Survival of dental implants placed in autogenous bone grafts and bone flaps in head and neck oncology patients: a systematic review. Int J Implant Dent 2018;4:19. DOI PubMed PMC

57. Frodel JL, Funk GF, Capper DT, et al. Osseointegrated implants: a comparative study of bone thickness in four vascularized bone flaps. Plast Reconstr Surg 1993;92:449-55; discussion 456-8. PubMed

58. Burgess M, Leung M, Chellapah A, Clark JR, Batstone MD. Osseointegrated implants into a variety of composite free flaps: a 
comparative analysis. Head Neck 2017;39:443-7. DOI PubMed

59. Mertens C, Freudlsperger C, Bodem J, Engel M, Hoffmann J, Freier K. Reconstruction of the maxilla following hemimaxillectomy defects with scapular tip grafts and dental implants. J Craniomaxillofac Surg 2016;44:1806-11. DOI PubMed

60. Schultes G, Gaggl A, Kärcher H. Stability of dental implants in microvascular osseous transplants. Plast Reconstr Surg 2002;109:91621; discussion 922-4. DOI PubMed

61. Frederick JW, Sweeny L, Carroll WR, Peters GE, Rosenthal EL. Outcomes in head and neck reconstruction by surgical site and donor site. Laryngoscope 2013;123:1612-7. DOI PubMed PMC 